\title{
Collagenous gastritis
}

\author{
Hugh J. Freeman, MD, James R.A. Piercey, MD, Robert J. Raine, MD
}

\begin{abstract}
A 54-year-old woman presented with nausea, vomiting and weight loss associated with impaired gastric emptying necessitating institution of parenteral nutrition. Subsequent studies revealed an unusual gastric mucosal inflammatory nrocess characterized by unique subepithelial collagenous deposits. Collagenous gastritis appears to be a distinct, possibly immune-mediated, chronic disorder, pathologically reminiscent of collagenous sprue and collagenous colitis. Can J Gastroenterol 1989;3(5):171-174

Key Words: Collagenous colitis, Collagenous sprue, Gastric histology, Gastritis

\section{Gastrite collagénique}

RESUME: Une patiente de 54 ans présente des nausées, des vomissements et une perte de poids liés à une détérioration de la vidange gastrique nécessitant l'institution d'une alimentation parentérale. Des études subséquentes révèlent un processus inflammatoire inhabituel de la muqueuse gastrique caractérisé par des dépôts sous-épithéliaux de collagène. La gastrite collagénique semble être une affection chronique distincte, peut-être d'origine immunitaire, dont la pathologie rappelle celle de la sprue collagénique et de la colite collagénique.
\end{abstract}

I: N 1970, WEINSTEIN ET AL (1) DESCRIBED a unique form of sprue - collagenous sprue - characterized clinically by refractory malabsorption and histopathologically by subepithelial collagen deposition in small intestinal biopsies. Similar histological features in the small intes-

Departments of Medicine (Gastroenterology), University Hospital and University of British Columbia, Vancouver; and Victoria General Hospital, Victoria, British Columbia

Correspondence and reprints: Dr Hugh Freeman, Gastroenterology, ACU F-137, University Hospital (UBC), 2211 Wesbrook Mall, Vancouver, British Columbia V6T 1W5. Telephone (604) 228-7216

Received for publication August 8, 1989. Accepted October 6, 1989 posits were seen and Lindstrom (5), in one of these reports, proposed the label collagenous colitis because of apparent pathological similarities to collagenous sprue. Since 1976, more than 50 patients with this disorder have been described and reviewed; in at least one patient both the small and large bowel were involved with the same process (7).

In the present report, a 54-year-old woman with a distinct form of gastritis is described. Clinical features suggested a progressive, possibly immune-mediated disorder, while gastric biopsies were characterized histopathologically by trichrome-positive, subepithelial collagenous deposits reminiscent of previously described changes in the small and large intestine of patients with collagenous sprue or collagenous colitis (1-7). Schein (2) and Hourihane (3). In 1976 , two reports independently described previously unrecognized histopathological features in colorectal biopsies from patients with chronic watery diarrhea $(4,5)$. Thick subepithelial collagenous de-

\section{CASE PRESENTATION}

A 54-year-old woman born in Scotland was initially seen in March 1979 with a three year history of anorexia, intermittent vomiting and weight loss of $14 \mathrm{~kg}$. She did not use alcohol, salicylates or other medications. Past history included a psychiatric admission in 1972 for depression; at that time, nausea and vomiting were apparently present. Examination revealed a weight of $38 \mathrm{~kg}$ and generalized muscle wasting. Gastroscopy 


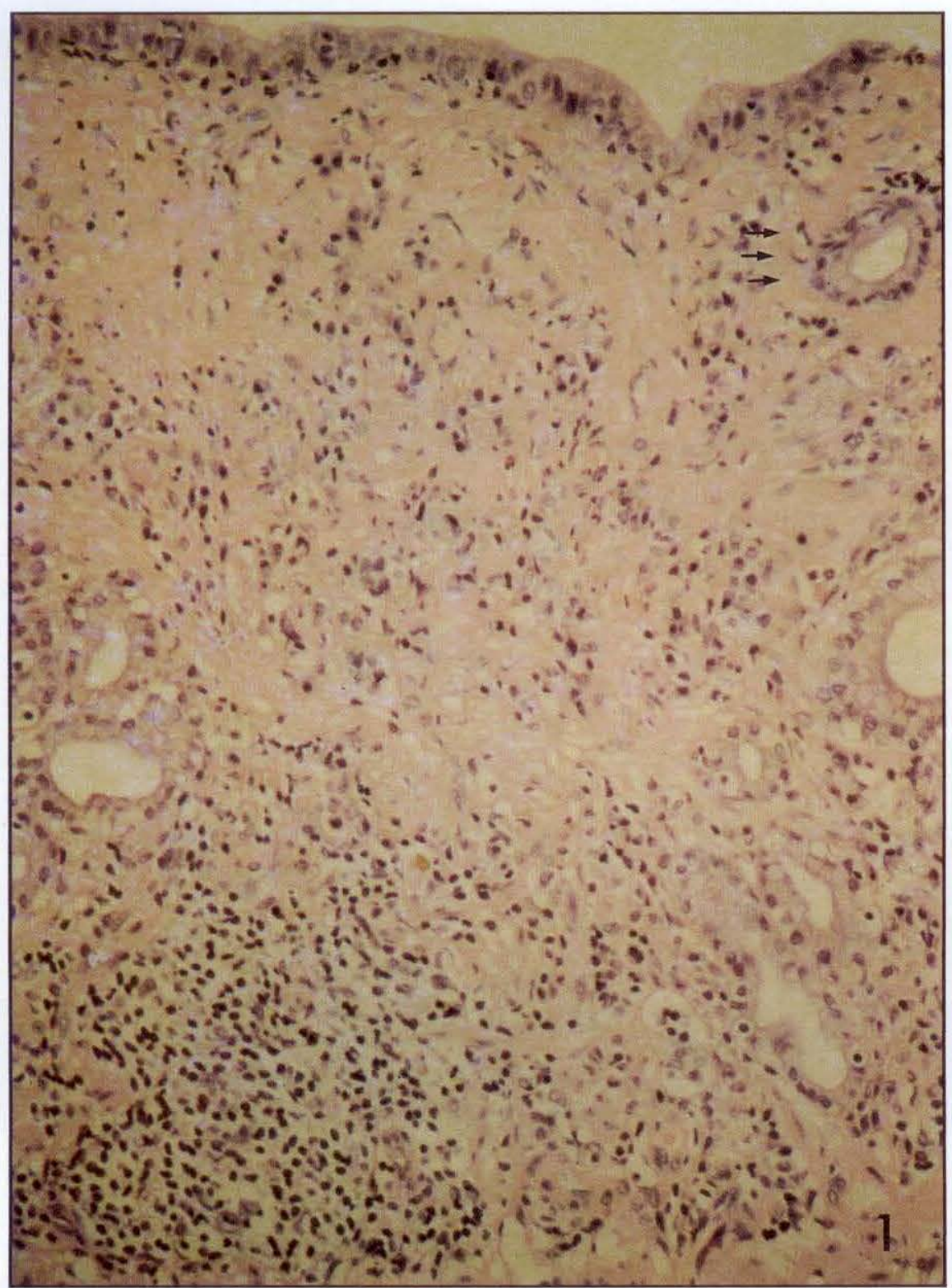

Figure 1) Gastric biopsy showing a dense subepithelial eosinophilic deposit with entrapped cells extending into the mucosa. Epithelial cells (arrows) also appear encased with hyaline material. The surface epithelium is intact but has a regenerative basophilic appearance with reduced gastric mucus. Scattered acute and chronic inflammatory cells are present along with a mucosal lymphoid aggregate and reduced glands. (Hematoxylin and eosin $\times 230$ )

was initially attempted prior to referral but rescheduled because of retained food residue; it was reported to show 'severe gastritis' with diffuse mucosal friability. As symptoms persisted despite treatment with antacids, cimetidine and metoclopramide, she was referred for evaluation.

Investigations included a normal hemoglobin of $123 \mathrm{~g} / \mathrm{L}$ and white cell count of $10,300 / \mathrm{mm}^{3}$ with a normal differential. Platelets, prothrombin time, activated partial thromboplastin time and fibrinogen were normal. Erythrocyte sed- imentation rate was $3 \mathrm{~mm} / \mathrm{h}$ (normal up to 20 ). Serum electrolytes, urea, creatinine, fasting and $2 \mathrm{~h}$ postprandial glucose, bilirubin, alkaline phosphatase, transaminases, uric acid, amylase, gastrin, ferritin, folic acid, vitamin B12, thyroxine and urinalysis were normal. Parietal cell antibodies, antinuclear antibodies and rheumatoid factor were negative. Syphilis serology was negative. Adrenocorticotrophic hormone-stimulated cortisols were normal. Total protein was reduced to $45 \mathrm{~g} / \mathrm{L}$ (normal 60 to 77 ) and serum albumin was reduced to $27 \mathrm{~g} / \mathrm{L}$ (normal 36 to 48). Immunoelectrophoresis and immunoglobulin quantitations (IgG, $\operatorname{IgM}, \operatorname{Ig} A$, IgE) were normal. Sigmoidoscopy and biopsy were normal. Chest x-ray, oral cholecystogram, intravenous pyelogram and barium $x$-rays of the upper and lower gastrointestinal tracts were normal. Abdominal ultrasound, bone, liver and gallium whole body scans as well as bone marrow aspiration were normal, with no evidence of neoplasia.

In hospital, attempts to introduce food and enteral nutrition supplements led to abdominal distension with severe nausea and vomiting. A succussion splash was detected and abdominal $\mathrm{x}$-rays revealed gastric dilation. Because of continuing nutritional deterioration, total parenteral nutrition was initiated. The patient's hospital course was subsequently complicated by bilateral aspiration pneumonia and hypoxemic respiratory failure with a pleural effusion. Pseudomonas aeruginosa was cultured, requiring intensive treatment with oxygen, physiotherapy and antibiotics. Sputum cytologies and thoracentesis of pleural fluid were negative for malignant cells and tuberculosis cultures were negative. Repeat endoscopies by two gastroenterologists confirmed the presence of patchy erythematous gastric mucosa without ulceration; mucosal vasculature appeared normal. Air insufflation of the stomach resulted in multiple freely bleeding petechial hemorrhages and marked mucosal friability. The duodenum was normal. Multiple mucosal biopsies from the gastric fundus, body and antrum revealed an 'acute gastritis' with polymorphonuclear leukocytes but no evidence of neoplasia. A search in the biopsy sections for candida and other organisms including spirochetes, Campylobacter pylori, cryptosporidium and cytomegalovirus was negative. Cultures of the gastric aspirate revealed $P$ aeruginos $a$ but no candida. Small bowel biopsies were normal. A gastrograffin swallow suggested impaired gastric emptying, but repeat barium studies of the upper and lower gastrointestinal tract were normal. A two week therapeutic trial of carbenoxalone resulted in hyperkalemia; cimetidine, metoclopramide and antacids were re- 


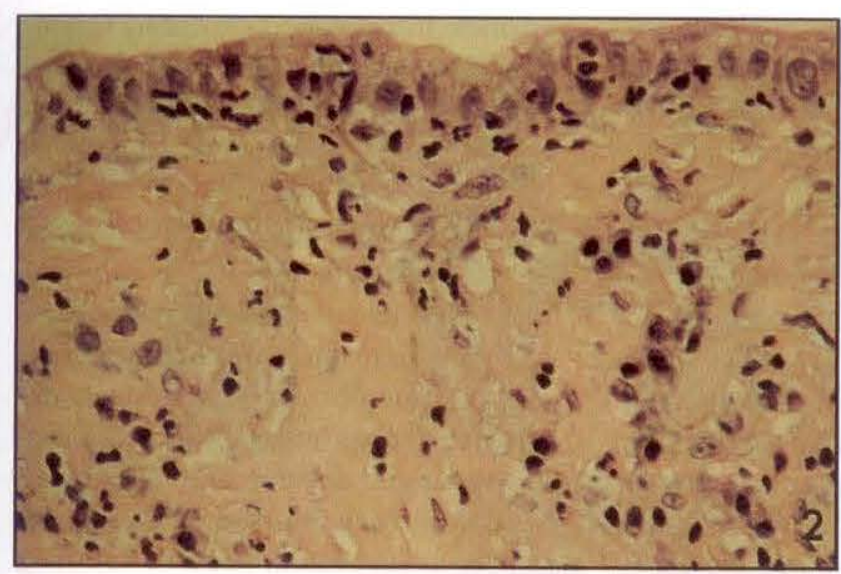

Figure 2) Higher power view of the surface epithelium and subepithelial region in Figure 1. Polymorphonuclear leukocytes are seen in the surface epithelium. A mixture of cell types including polymorphonuclear leukocytes and plasma cells are entrapped in the subepithelial hyaline deposit. (Hematoxylin and eosin $\times 295$ )

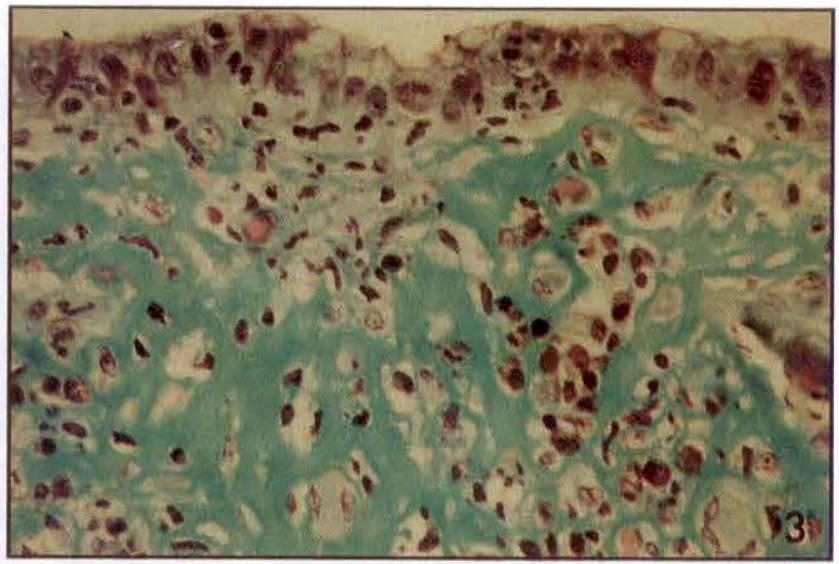

Figure 3) The subepithelial hyaline deposit stains positively with ${ }^{22}$ trichrome in a gastric biopsy section adjacent to that shown in Figure 2, indicative of collagen deposition. (Trichrome $\times 295$ ) instituted. Respiratory and nutritional status improved with an increase in weight to $47 \mathrm{~kg}$. Nausea and vomiting abated permitting oral intake but this was variable ranging from 600 to 1800 $\mathrm{kcal} /$ day.

The patient was discharged in May 1979 but required readmission in $\mathrm{Au}$ gust 1979 because of deteriorating respiratory status, redevelopment of nausea and vomiting, and weight loss to $36 \mathrm{~kg}$. Repeated blood tests revealed continuing hypoproteinemia and hypoalbuminemia, with the appearance on peripheral blood smears of Howell-jolly bodies. Parenteral nutrition was reinstituted. Liver-spleen scan revealed no splenic activity. Bone marrow biopsy was normal. Chest $\mathrm{x}$-ray and bronchograms suggested bronchitis and early bronchiectasis. Pulmonary function studies were consistent with airflow obstruction. Lymphangiogram of the lower limbs, inguinal, iliac and periaortic lymph nodes was normal. Pentagastrin-stimulated gastric analysis revealed no titratable acid, and a repeat barium study suggested slight narrowing of the gastric antrum. Gastroscopy revealed only hyperemia with diffuse mucosal friability; biopsies revealed no neoplastic cells. Persisting pulmonary sepsis required continuing antimicrobial therapy and parenteral nutrition was reinitiated.

Because of persistent nausea and inability to eat, an exploratory laparotomy was done in October 1979. The stom- ach appeared pale and prominent rugal folds with a 'gritty texture' were described. An atrophic spleen was resected and showed fibrosis. Liver biopsy revealed some bile stasis consistent with cholestasis associated with parenteral nutrition. Full thickness gastric biopsies were done. Oral intake continued to deteriorate and was estimated to be 500 to $600 \mathrm{kcal} /$ day and prednisone $10 \mathrm{mg}$ bid was started. During admission eye pain developed and filamentary keratopathy was observed. Tear secretion was absent on a Schirmer's test and a diagnosis of Sjögren's syndrome was made. Respiratory deterioration continued; the course was complicated by a fatal pulmonary embolism.

Autopsy: Autopsy revealed buccal mucosal subepithelial inflammation consisting predominantly of lymphocytes. In addition, salivary gland lobules showed atrophy with a lymphocytic inflammatory change. Extensive bronchiectasis was present in both lower lobes of the lungs. Although the gastrointestinal mucosa was severely autolyzed, full thickness gastric biopsies from the laparotomy were reviewed; these confirmed the presence of gastritis with increased lamina propria lymphocytes and plasma cells. Glands were reduced in number and numerous polymorphonuclear leukocytes were noted in the surface epithelium and lamina propria. No neoplastic cells were present and amyloid stains were negative. A prominent extracellular sub- epithelial band of eosinophilic material was observed with entrapped cells; this material was trichrome-positive, typical of collagen and similar to features in collagenous sprue (1) and collagenous colitis (5).

Endoscopic biopsies prior to laparotomy: These included six gastric biopsies from body and antrum in March 1979, and one gastric body biopsy in September 1979. Of these, one gastric antral biopsy done in March 1979 showed a focal area of subepithelial collagen deposition. No deposits were identified in the other six gastric biopsies, two biopsies from the small intestine and one rectal biopsy.

\section{DISCUSSION}

This report illustrates a unique gastric mucosal inflammatory process characterized histopathologically by the presence of dense subepithelial collagenous deposits. Clinically, the patient had markedly impaired gastric emptying and achlorhydria. These histopathological changes in gastric biopsies are similar to those reported in the subepithelial regions of small and large bowel mucosal biopsies from patients with collagenous sprue (1) and collagenous colitis (5). The entity described here appears to be distinct from other previously described forms of gastritis and is labelled collagenous gastritis.

This entity shares some apparently common clinical features with those al- 
ready observed in patients with collagenous sprue and collagenous colitis. As in the present case, most patients described with small or large intestinal involvement are female with a mean age of more than 50 years $(6-8)$. The clinical course of these disorders appears to be chronic with persistent or intermittent symptoms. In collagenous sprue, refractory malabsorption is usually present (1) and parenteral nutrition may be required to permit survival, while in collagenous colitis, chronic watery diarrhea is evident. Although there are some anecdotal reports of successful drug treatment of collagenous sprue (9) and collagenous colitis (10-12), patient numbers in most series are small and duration of follow-up is usually limited. An immune-mediated pathogenesis has been suggested for both collagenous sprue and collagenous coli-

ACKNOWLEDGEMENTS: The authors acknowledge the excellent secretarial assistance of Mrs Wendy Semko and Mrs Cec Taerg.

\section{REFERENCES}

1. Weinstein WM, Saunders DR, Tytgat

GN, Rubin CE. Collagenous sprue -

An unrecognized type of malabsorption. N Engl J Med 1970;283:1297-301.

2. Schein J. Syndrome of nontropical sprue with hither-to undescribed lesions of the intestine, Gastroenterology 1947:8:438-60.

3. Hourihane DO'B. The histology of intestinal biopsies. Proc Royal Soc Med 1963;56:1073-7.

4. Freeman HJ, Weinstein WM, Shnitka TK, Wensel RH, Sartor VE. Watery diarrhea syndrome associated with a lesion of the colonic basement membrane-lamina propria interface. Ann Royal Coll Phys Surg Can 1976;9:45.

5. Lindstrom CG. "Collagenous colitis" with watery diarrhea - A new entity? Path Eur 1976;11:87-9.

6. Freeman HJ. Collagenous colitis. In: Freeman HJ, ed. Inflammatory Bowel Disease, Vol 2. Boca Raton: CRC Press, 1989:75-81.

7. Eckstein RP, Dowsett JF, Riley JW. Collagenous enterocolitis: A case of tis; in the latter, extraintestinal 'autoimmune' features have been observed including arthritis (12-14), thyroid disease (15) and pulmonary fibrosis (16).

In the present patient, clinical and pathological features typical of Sjögren's syndrome appeared. She also developed features of functional hyposplenism. Howell-jolly bodies appeared in peripheral blood smears associated with an absence of splenic radionuclide uptake at laparotomy, fibrosis of the spleen was discovered. Lymphoreticular dysfunction with hyposplenism and splenic atrophy or fibrosis may accompany several gastrointestinal disorders including celiac sprue and dermatitis herpetiformis, intestinal lymphoma, mesenteric lymph node cavitation syndrome and inflammatory bowel disease (17-21). Studies in this patient excluded each of these

collagenous colitis with involvement of the small intestine. Am J Gastroenterol 1988;83:767-71.

8. Rams H, Rogers AI, GhandurMnaymneh L. Collagenous colitis. Ann Intern Med 1987;106:108-13.

9. Holdstock DJ, Oleesky S. Successful treatment of collagenous sprue with combination of prednisolone and gluten-free diet. Postgrad Med J 1973;49:664-7.

10. Pieterse AS, Hecker R, Rowland R. Collagenous colitis: A distinctive and potentially reversible disorder. J Clin Pathol 1982;35:338-40.

11. Weidner N, Smith J, Pattee B. Sulfasalazine in treatment of collagenous colitis: Case report and review of the literature. Am J Med 1984;77:162-6.

12. Farah DA, Mills PR, Lee FD, McLay A, Russell RI. Collagenous colitis: Possible response to sulfasalazine and local steroid therapy. Gastroenterology 1985;88:792-7.

13. Erlendsson J, Fenger C, Meinicke J. Arthritis and collagenous colitis. Scand J Rheumatol 1983;12:93-5.

14. Wengrower D, Pollak A, Okon E, Stalnikowicz R. Collagenous colitis and rheumatoid arthritis with response to sulfasalazine. A case report and review of the literature. J Clin Gastroenterol 1987;9:456-60.

15. Giardiello FM, Bayless TM, Jessurun J, entities; in retrospect, reduced splenic function probably contributed to the continuing respiratory sepsis.

This report describes a new form of gastric mucosal inflammatory disease, collagenous gastritis, in a middle-aged female with defective gastric emptying and achlorhydria; associated disorders in this patient included hyposplenism with splenic fibrosis, progressively deteriorating respiratory sepsis with bronchiectasis and development of Sjögen's syndrome. An immune-mediated pathogenesis is suspected, possibly resulting in altered function of lamina propria fibroblasts, cells thought to be important in collagen production and deposition in the epithelial basement membrane region of the gastrointestinal tract. Treatment of collagenous gastritis is, at this time, unknown.

Hamilton SR, Yardley JH. Collagenous colitis: Physiologic and histopathologic studies in seven patients. Ann Intern Med 1987;106:46-9.

16. Wiener MD. Collagenous colitis and pulmonary fibrosis. Manifestations of a single disease? J Clin Gastroenterol 1986;8:677-80

17. McCarthy CF, Fraser ID, Evans KT, Read AE. Lymphoreticular dysfunction in idiopathic steatorrhea. Gut 1966;7:140-8.

18. Marsh GW, Stewart JS. Splenic function in adult coeliac disease. $\mathrm{Br} J$ Haematol 1970;19:445-57.

19. Freeman HJ, Weinstein WM, Shnitka TK, Piercey JRA, Wensel RH. Primary abdominal lymphoma: Presenting manifestation of celiac sprue or complicating dermatitis herpetiformis. Am J Med 1977:63:585-94

20. Matuchansky C, Colin R, Hemet J, et al. Cavitation of mesenteric lymph nodes, splenic atrophy, and a flat small intestinal mucosa. Gastroenterology 1984;87:606-14

21. Freeman HJ, Chiu BK. Small bowel malignant lymphoma complicating celiac sprue and the mesenteric lymph node cavitation syndrome. Gastroenterology 1986;90:2008-12.

22. Culling CFA. Handbook of Histopathological and Histochemical Techniques, 3rd edn. London: Butterworths, 1974:414-6. 


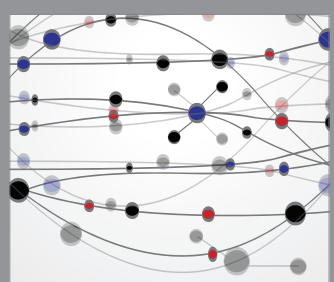

The Scientific World Journal
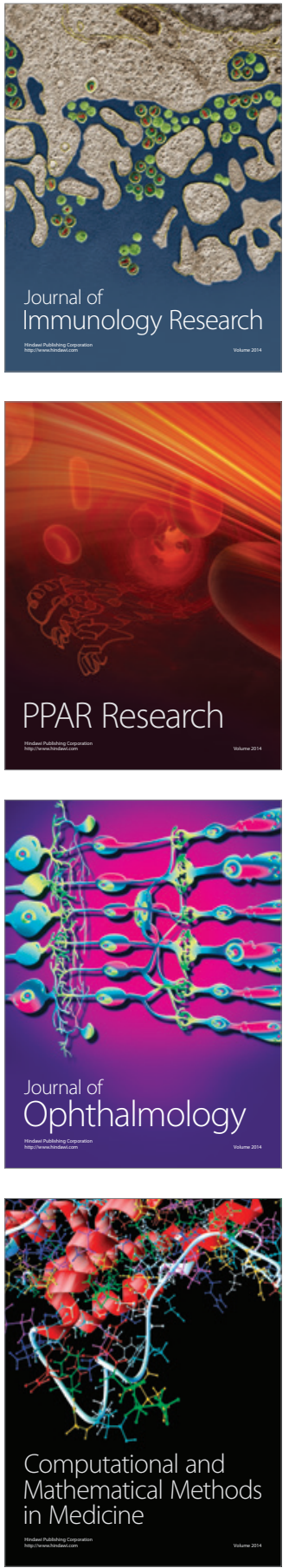

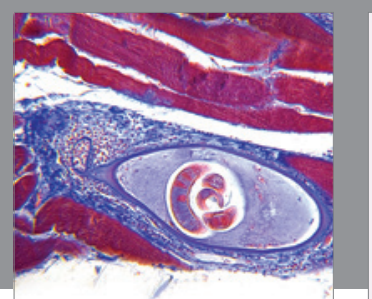

Gastroenterology Research and Practice

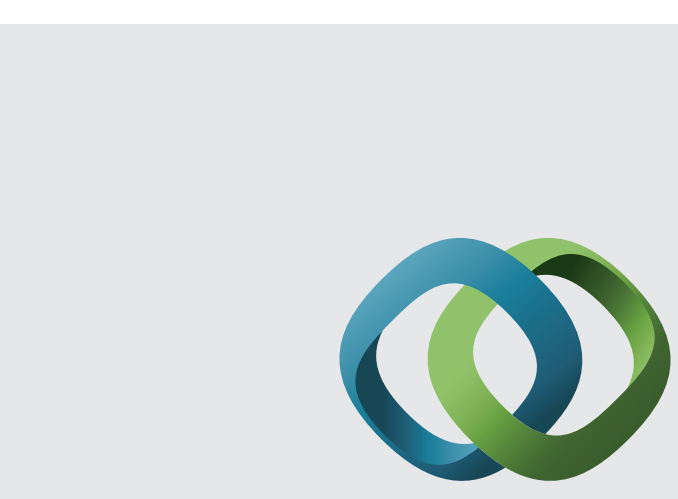

\section{Hindawi}

Submit your manuscripts at

http://www.hindawi.com
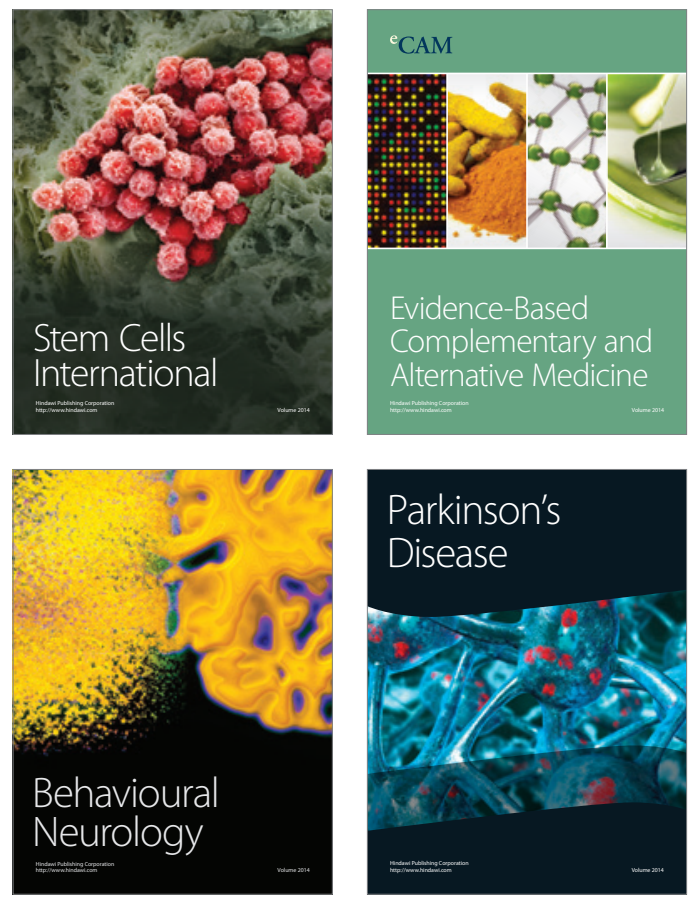
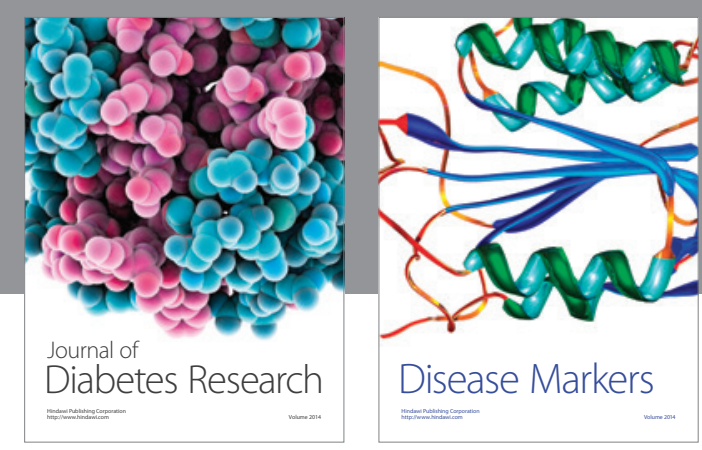

Disease Markers
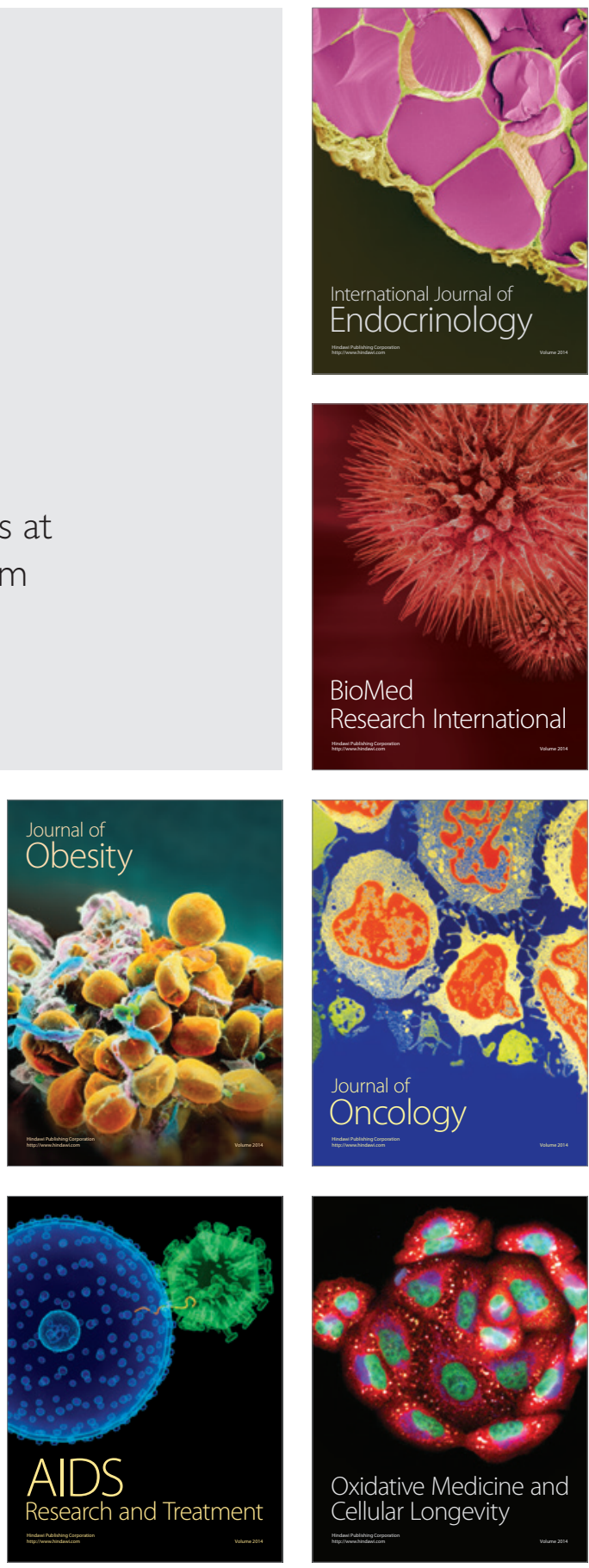